\title{
Beneficial Effect of Cissus quadrangularis Linn. on Osteopenia Associated with Streptozotocin-Induced Type 1 Diabetes Mellitus in Male Wistar Rats
}

\author{
Srinivasa Rao Sirasanagandla, ${ }^{1}$ Sreedhara Ranganath Pai Karkala, ${ }^{2}$ Bhagath Kumar Potu, ${ }^{3}$ \\ and Kumar M.R. Bhat ${ }^{4}$ \\ ${ }^{1}$ Department of Anatomy, Melaka Manipal Medical College, Manipal University, Madhav Nagar, Manipal, Karnataka 576104, India \\ ${ }^{2}$ Department of Pharmacology, Manipal College of Pharmaceutical Sciences, Manipal University, Manipal, Karnataka 576104, India \\ ${ }^{3}$ Department of Anatomy, College of Medicine and Medical Sciences, Arabian Gulf University, P.O. Box 26671, Bahrain \\ ${ }^{4}$ Department of Anatomy, Kasturba Medical College, Manipal University, Manipal, Karnataka 576104, India
}

Correspondence should be addressed to Kumar M.R. Bhat; kummigames@yahoo.com

Received 6 January 2014; Revised 3 March 2014; Accepted 3 March 2014; Published 7 April 2014

Academic Editor: Antonio Ferrer-Montiel

Copyright (c) 2014 Srinivasa Rao Sirasanagandla et al. This is an open access article distributed under the Creative Commons Attribution License, which permits unrestricted use, distribution, and reproduction in any medium, provided the original work is properly cited.

\begin{abstract}
Petroleum ether fraction of Cissus quadrangularis (PECQ) impact on the development of osteopenia in type 1 diabetic rat model has been evaluated. Diabetic rats were treated orally with two doses of PECQ. Another group of diabetic rats were treated with subcutaneous injection of synthetic human insulin. The cortical and trabecular bone thickness and bone strength were significantly decreased in diabetic rats. Treatment with two doses of PECQ significantly prevented these changes in diabetic rats. However, $P E C Q$ treatment (two doses) did not alter the glycemic levels in these diabetic rats. Increased levels of serum alkaline phosphatase (ALP), tartrate-resistant acid phosphatase (TRAP), and hydroxyproline were noted in diabetic rats when compared to normal control rats. The two doses of PECQ treatment further improved the serum ALP levels and significantly decreased the serum levels of TRAP and hydroxyproline. The effects of PECQ treatment on histological, biomechanical, and biochemical parameters are comparable to those of insulin. Since PECQ improves the bone health in hyperglycemic conditions by enhancing the cortical and trabecular bone growth and altering the circulating bone markers, it could be used as an effective therapy against diabetes-associated bone disorders.
\end{abstract}

\section{Introduction}

Diabetes mellitus (DM) is a combination of metabolic disorders characterized by impaired metabolism of carbohydrates, proteins, and fat resulting from insulin deficiency [1]. Skeletal disorders are common in diabetic patients, namely, reduced bone mineral content $[2,3]$, deranged calcium and phosphate levels, and altered bone metabolism [3-6]. Osteopenia [7], increased risk of fractures [8], and delayed fracture healing [9] are evident in these patients. Earlier, animal models have proved the association between osteopenic/osteoporotic changes and type $1 \mathrm{DM}[10-15]$. It has been demonstrated that the adverse effects of DM on bone tissue could be due to insulinopenia, bone microangiopathy, impaired regulation of mineral metabolism, and alterations in local factors that regulate bone remodeling $[16,17]$. Dimensions of the femur such as weight, length, and diaphyseal width were found to be decreased in diabetic rats [18]. Furthermore, experimental studies have demonstrated that the mechanical strength of bones is reduced in diabetic rats [19-21]. Diabetes is also found to delay fracture healing and treatment with synthetic calcium phosphate or hydroxyapatite has been shown to have a positive effect on fracture healing [22-24]. It was also shown that the treatment with either insulin or 17-b estradiol (E2) can reverse the altered architecture of bones in diabetic rats and their effects were found to be similar [25]. Verhaeghe et al. have observed the positive effect of E2 against the metaphyseal trabecular bone damage in ovariectomized 
diabetic rats, when compared to nontreated control rats [26].

Cissus quadrangularis (CQ) is a climbing shrub, which belongs to the Vitaceae family. It is usually seen in hot climate in various states of India, Sri Lanka, Malaya, Java, and West Africa [27]. In Ayurveda, its usage in the treatment of bone fractures and swelling has been mentioned [28]. $C Q$ has been shown to have an ability to accelerate the healing of bone fracture [29]. Experimental animal models have proved the antiosteoporotic potential of ethanol, petroleum ether, and hexane fractions of the CQ [27, 30, 31]. A pharmacological study on $C Q$ has shown the presence of phytoestrogen steroids [32]. Recently, the phytoestrogenrich fraction separated from the $C Q$ has been shown to have potent antiosteoporotic activity [33]. In vitro study has shown that the petroleum ether fraction of CQ (PECQ) enhances the proliferation and differentiation of rat bone marrow mesenchymal stem cells [34]. Previously in our laboratory, the protective effect of PECQ on defective fetal skeletal ossification in maternal diabetes has been studied (ahead of print). Though the pharmacological effect of CQ on bone health has been studied extensively, no attempt has been made to study the efficacy of CQ on osteopenia associated with DM. In the presented study, we evaluated the effect of CQ against bone histology, biomechanical changes, and circulating bone markers in type 1 diabetic rats.

\section{Material and Methods}

2.1. Preparation of Plant Extract. The fresh stems of CQ were air-dried and grinded into powder. Using a soxhlet apparatus, $1.3 \mathrm{~kg} C Q$ powder was subjected to extraction with $95 \%$ ethyl alcohol. The ethanol extract obtained (125g) was further suspended in water. Then, it was partitioned with petroleum ether (b.p. $\left.60-90^{\circ} \mathrm{C}\right)$ solvent. The total yield $(9.1 \% \mathrm{w} / \mathrm{w})$ of $P E C Q$ was stored at $4^{\circ} \mathrm{C}$ until use. Every day fresh suspension of PECQ was prepared by using carboxymethyl cellulose (CMC).

2.2. Animals. In the present study, 3-month-old male Wistar rats (180-220 g weight) were used. After obtaining approval from the Institutional Animal Ethical Committee, rats were placed in the Central animal research facility of Manipal University according to guidelines of the Committee for the Purpose of Control and Supervision of Experiments on Animals (CPCSEA). Proper ventilation with temperature control was maintained on a $12 \mathrm{hr}$ dark and $12 \mathrm{hr}$ light schedule throughout the experiment. Rats were fed a standard balanced diet and water.

2.3. Induction of Diabetes and Treatments. After one week male Wistar rats were induced diabetes with streptozotocin (STZ) injection intraperitoneally ( $40 \mathrm{mg} / \mathrm{kg}$ body weight), which was dissolved in $0.1 \mathrm{M}$ citrate buffer, $\mathrm{pH} 4.5$. Control rats were injected $0.1 \mathrm{M}$ citrate buffer. The blood glucose levels were analyzed seven days after injection using Glucometer (AccuChek Active). Animals demonstrating hyperglycemia ( $>250 \mathrm{mg} / \mathrm{dL}$ ) were treated orally with PECQ at daily doses of
$500 \mathrm{mg} / \mathrm{kg}$ and $750 \mathrm{mg} / \mathrm{kg}$ body weight. The dose was selected based on the previous study [30]. The diabetic rats in another group were injected subcutaneously twice daily with human synthetic insulin (INS) (Actrapid, Novo Nordisk India Pvt. Ltd., India), at a dose of $10 \mathrm{U} / \mathrm{kg}$ body weight. Treatment continued for 45 days.

2.4. Experimental Design. Experimental rats $(n=30)$ were allocated to 5 groups each containing 6 rats. Rats in normal control (NC) Group A received 0.5\% CMC; Group B, diabetic control group (DC), received 0.5\% CMC; Group C, the diabetic + CQ1 group (DC + CQ1), received $500 \mathrm{mg} / \mathrm{kg}$ body weight dose of PECQ; Group D, the diabetic + CQ2 group (DC + CQ2), received $750 \mathrm{mg} / \mathrm{kg}$ body weight dose of PECQ; and Group E, the diabetic + INS group (DC + INS), rats received INS. The blood glucose levels were analyzed at regular intervals of the experimental period. Following the completion of experiment, the animals were sacrificed under anesthesia by cervical dislocation. Before sacrificing the animals, blood was collected for estimation of serum ALP, TRAP, and hydroxyproline. Right femora were collected for histomorphometrical analysis of trabecular bone and cortical bone. Left femora were stored at $-70^{\circ} \mathrm{C}$ for testing the biomechanical properties. Right tibia was collected for measuring the dry weight.

2.5. Histomorphometrical Analysis. Left femora were dissected and the soft tissue separated. Tissues were fixed in the PLP fixative for $24 \mathrm{hr}$ at $4^{\circ} \mathrm{C}$. Then, the femora were subjected to decalcification using EDTA-glycerine solution. After 20 days of complete decalcification, tissues were dehydrated and placed in paraffin wax. The longitudinal sections $(5 \mu \mathrm{m}$ thickness) of the lower end of the femur were taken on rotary microtome and then processed for eosin and hematoxylin staining. The stained sections were used for analysis of the thickness of trabecular bone in the metaphyseal and epiphyseal regions, by using Olympus Cellsens Imaging Software (1.6 version, USA).

2.6. Measurement of Biomechanical Properties. The maximum flexor load was measured by a three-point bending test, using a Universal testing 3366 machine (Instron Corp, UK). Briefly, the left femora were brought to room temperature from $-70^{\circ} \mathrm{C}$ and wiped with tissue paper. In the material testing machine, the bone was placed horizontally on two supports and load was applied in the middle of the shaft, at a speed of $5 \mathrm{~mm} / \mathrm{min}$ until the bone was fractured.

2.7. Biochemical Analysis of Serum Bone Markers. ALP and TRAP levels were estimated by spectrophotometric method, using commercially available kits (Agappe diagnostics). Serum hydroxyproline levels were analyzed by Neuman and Logan method [35].

2.8. Dry Weight of the Tibia. Right tibia were collected and dissected free of soft tissue. Bone tissues were kept in a hot-air oven at $110^{\circ} \mathrm{C}$ for $48 \mathrm{hr}$ and were weighed in digital balance as described previously [36]. 
TABLE 1: Effect of PECQ on blood glucose levels (mg/dL) in diabetic rats.

\begin{tabular}{lcccccc}
\hline Groups & Day 0 & Day 5 & Day 15 & Day 25 & Day 35 & Day 45 \\
\hline NC & $89 \pm 5.71$ & $97.16 \pm 5.02$ & $92.5 \pm 3.51$ & $95.5 \pm 4.58$ & $99.83 \pm 4.86$ & $105.33 \pm 5.14$ \\
DC & $294.5 \pm 9.66^{* * *}$ & $351.16 \pm 23.5^{* * *}$ & $390 \pm 18.44^{* * *}$ & $394 \pm 19.52^{* * *}$ & $398 \pm 26.51^{* * *}$ & $381 \pm 21.59^{* * *}$ \\
DC + CQ1 & $305 \pm 13.8$ & $342.66 \pm 21.12$ & $374.5 \pm 14.49$ & $379.5 \pm 19.97$ & $372.83 \pm 23.65$ & $375 \pm 25.91$ \\
DC + CQ2 & $308.66 \pm 13.48$ & $346.33 \pm 14.25$ & $364.66 \pm 22.08$ & $365 \pm 19.81$ & $379 \pm 26.61$ & $378.5 \pm 17.49$ \\
DC + INS & $292.66 \pm 9.05$ & $102.83 \pm 6.35^{\$ \$}$ & $109.5 \pm 6.14^{\$ \$}$ & $99.16 \pm 4.63^{\$ \$ \$}$ & $117.16 \pm 5.31^{\$ \$ \$}$ & $103.83 \pm 6.1^{\$ \$}$ \\
\hline
\end{tabular}

${ }^{* * *} P<0.001$ when compared to NC group. ${ }^{\$ \$} P<0.001$ when compared to DC group.

2.9. Statistical Analysis. Results were expressed as the mean \pm standard error of mean. Data was analyzed by using Graphpad Prism (version 5.1). One-way ANOVA followed by Bonferroni's multiple comparison test was used to evaluate differences between groups. Statistical significance was considered at $P<0.05$.

\section{Results}

3.1. Effect of PECQ on Blood Glucose Levels. DC rats had hyperglycemia $(>250 \mathrm{mg} / \mathrm{dL})$ throughout the experiment. The two doses of PECQ treatment did not alter the blood glucose levels in diabetic rats when compared to diabetic nontreated rats $(P>0.05$; Table 1$)$. However, insulin treatment significantly decreased the blood glucose levels, when compared to DC group $(P<0.001$; Table 1$)$.

3.2. Effect of PECQ on Trabecular Bone in Epiphyseal Region. DC rats had thinner trabeculae in the epiphyseal region $(P<$ 0.001; Figures 1(a) and 1(b)) when compared to NC rats suggesting that the hyperglycemia affects the normal bone architecture and leads to bone loss in the epiphyseal region. Treatment with PECQ significantly improved the trabecular bone thickness in the DC + CQ1 $(P<0.01$; Figures $1(\mathrm{a})$ and $1(\mathrm{~b}))$ and $\mathrm{DC}+\mathrm{CQ} 2(P<0.001$; Figures $1(\mathrm{a})$ and 1(b)) groups when compared to DC rats. On the other hand, metabolic control with INS significantly prevented the bone loss in diabetic rats $(P<0.001$; Figures $1(\mathrm{a})$ and $1(\mathrm{~b}))$ when compared to DC rats.

3.3. Effect of PECQ on Trabecular Bone in Metaphyseal Region. Thinner trabeculae were observed in the DC rats $(P<0.001$; Figures 2(a) and 2(b)) when compared to NC rats, suggesting that hyperglycemia also affects the bone growth in the metaphyseal region. Treatment with two doses of $P E C Q$ significantly improved the trabecular bone thickness in $\mathrm{DC}+\mathrm{CQ} 1$ and DC + CQ2 groups $(P<0.01$; Figures $2(\mathrm{a})$ and $2(\mathrm{~b}))$ when compared to diabetic nontreated rats. INS treatment also significantly improved the bone thickness in DC + INS rats $(P<0.001$; Figures 2(a) and 2(b)) when compared to diabetic nontreated rats.

3.4. Effect of PECQ on Cortical Bone. The thickness of cortical bone significantly decreased in the DC group $(P<0.001$; Figures 3(a) and 3(b)) when compared to NC rats, indicating the effect of hyperglycemia on cortical bone loss. PECQ treatment significantly improved the cortical bone thickness
TABLE 2: Effects of PECQ on serum bone markers in diabetic rats.

\begin{tabular}{lccc}
\hline Groups & $\begin{array}{c}\text { ALP } \\
(\mathrm{U} / \mathrm{L})\end{array}$ & $\begin{array}{c}\text { TRP } \\
(\mathrm{U} / \mathrm{L})\end{array}$ & $\begin{array}{c}\text { Hydroxyproline } \\
(\mu \mathrm{g} / \mathrm{mL})\end{array}$ \\
\hline NC & $96.45 \pm 5.93$ & $6.40 \pm 0.29$ & $0.233 \pm 0.008$ \\
DC & $188.7 \pm 7.02^{* * *}$ & $8.52 \pm 0.19^{* * *}$ & $0.285 \pm 0.007^{* *}$ \\
$\mathrm{DC}+\mathrm{CQ} 1$ & $217.3 \pm 9.4^{* * *}$ & $6.90 \pm 0.24^{\$}$ & $0.250 \pm 0.007^{\$}$ \\
DC + CQ2 & $223.3 \pm 13.21^{* * *}$ & $6.74 \pm 0.40^{\$ \$}$ & $0.249 \pm 0.009^{\$}$ \\
DC + INS & $229.1 \pm 9.75^{* * *}$ & $6.57 \pm 0.37^{\$ \$}$ & $0.239 \pm 0.009^{\$ \$}$ \\
\hline *** $P<0.001,{ }^{* *} P<0.01$ when compared to NC group. ${ }^{\$} P<0.01,{ }^{\$} P<$ \\
0.05 when compared to DC group.
\end{tabular}

in the DC + CQ1 $(P<0.01$; Figures 3(a) and 3(b)) and $\mathrm{DC}+\mathrm{CQ} 2(P<0.001$; Figures 3(a) and 3(b)) groups when compared to DC rats. INS treatment also significantly improved the cortical bone thickness in diabetic rats $(P<0.001$; Figures 3(a) and 3(b)) when compared to diabetic nontreated rats.

3.5. Effect of PECQ on Biomechanical Strength. Mean maximum flexor load $(\mathrm{N})$ required to produce break in the femur of NC, DC, DC + CQ1, DC + CQ2, and DC + INS groups was $96.53 \pm 5.37,53.2 \pm 5.03,76.47 \pm 4.4$, $81.42 \pm 6.24$, and $91.53 \pm 4.79$ newtons, respectively. Mean maximum flexor load was significantly less in the diabetic nontreated rats $(P<0.001$; Figure 4$)$, when compared to nondiabetic control rats. Further, mean maximum flexor load was significantly more in DC + CQ1 $(P<0.05)$, DC + CQ2 $(P<0.01)$, and DC + INS $(P<0.001)$ groups when compared to DC rats (Figure 4).

3.6. Effect of PECQ on Dry Weight of Tibia. Dry weight of the tibia measured in NC, DC, DC + CQ1, DC + CQ2, and DC + INS groups was $0.42 \pm 0.019,0.26 \pm 0.017,0.35 \pm 0.013$, $0.36 \pm 0.021$, and $0.39 \pm 0.022$ grams, respectively. Bone weight was significantly decreased in the DC rats $(P<0.001$; Figure 5), when compared to NC rats. Dry weight was significantly increased in all the treated groups, DC + CQ1 $(P<0.05), \mathrm{DC}+\mathrm{CQ} 2(P<0.05)$, and DC $+\mathrm{INS}(P<0.001)$, when compared to DC rats (Figure 5).

3.7. Effect of PECQ on ALP, TRAP, and Hydroxyproline. Serum ALP levels were significantly increased in diabetic nontreated animals $(P<0.001$; Table 2$)$ when compared to NC group. Increased ALP levels confirm that diabetes induces bone damage. Serum ALP levels further increased 


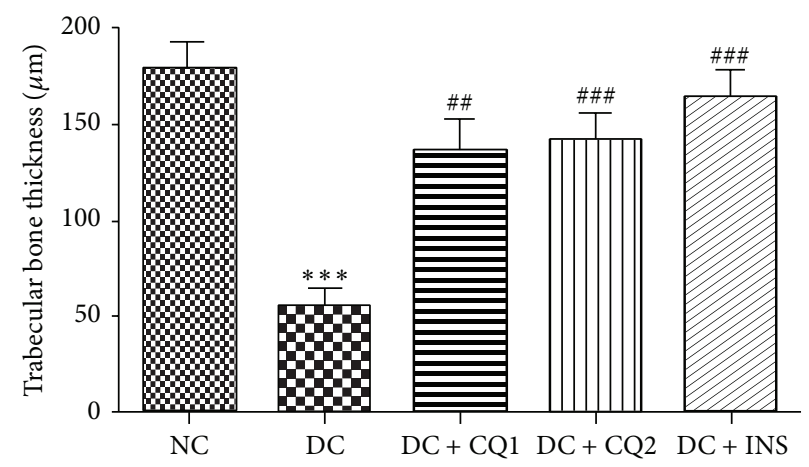

(a)
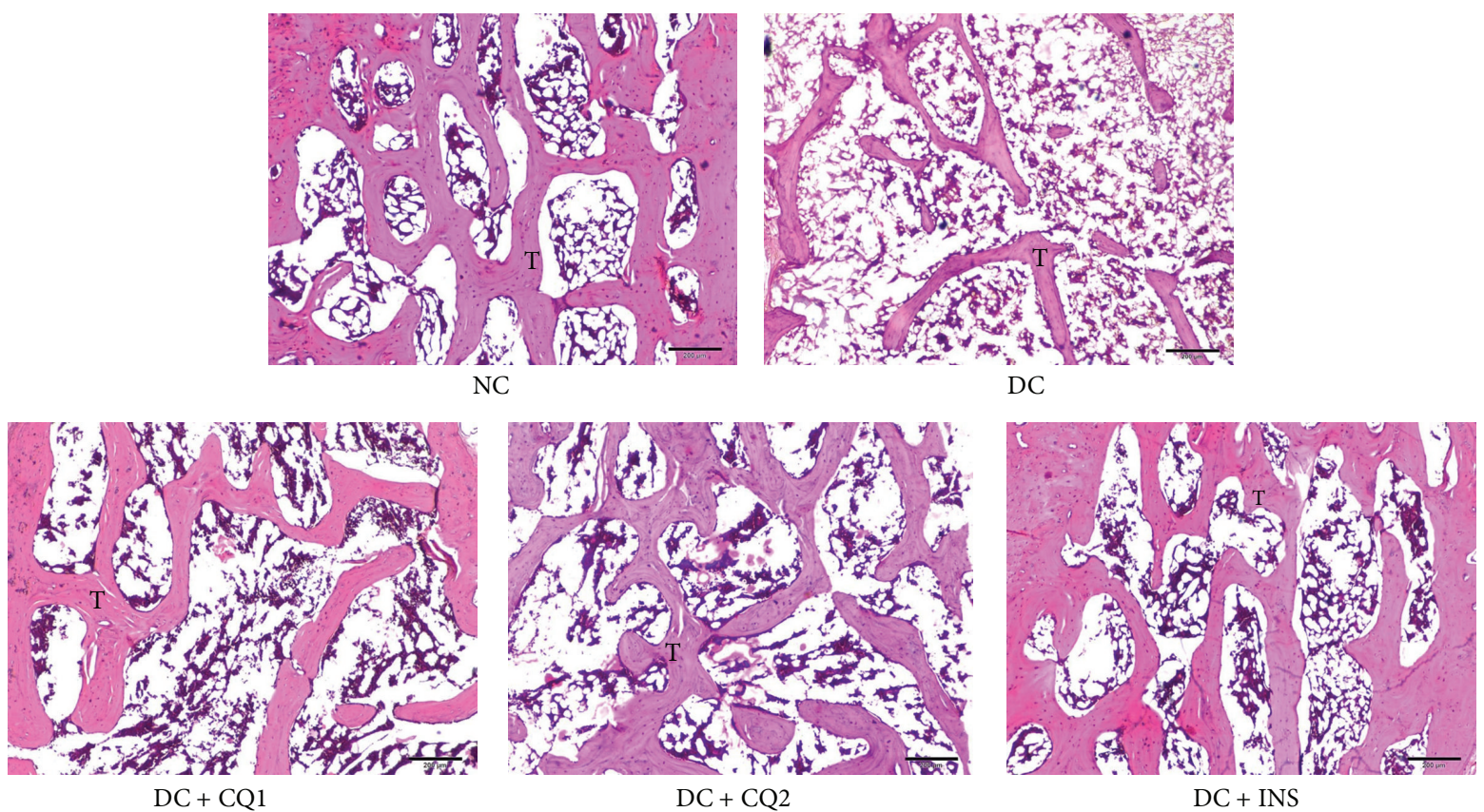

(b)

Figure 1: (a) Effect of PECQ on mean thickness of trabecular bone in the epiphyseal region. Significant decrease in the thickness of the trabecular bone was observed in the diabetic control (DC) rats when compared to normal control (NC) rats. However, diabetic rats treated with two different doses of PECQ (DC + CQ1 \& DC + CQ2) or with insulin (DC + INS) showed a significant increase in bone thickness. ${ }^{* * *} P<0.001$ when compared to NC group; ${ }^{\# \# \#} P<0.001,{ }^{\# \#} P<0.01$ when compared to DC group. (b) Photomicrographs of trabecular bone in epiphyseal region. Thinner and reduced number of trabeculae can be seen in the diabetic control group (DC) when compared to normal control group (NC). Further treatment with two doses of PECQ (DC + CQ1, DC + CQ2) and insulin (DC + INS) improved the trabecular bone thickness. T: trabecular bone; $\mathrm{H}$ and $\mathrm{E}$ staining, scale bar: $200 \mu \mathrm{m}$.

in $\mathrm{DC}+\mathrm{CQ} 1(P<0.001), \mathrm{DC}+\mathrm{CQ} 2(P<0.001)$, and DC + INS $(P<0.001)$ groups when compared to NC group (Table 2). This result shows that both PECQ and metabolic control with INS enhance the bone formation and mineralization process in hyperglycemic conditions. When compared to NC group, serum levels of TRAP $(P<0.001$; Table 2$)$ and hydroxyproline $(P<0.01$; Table 2$)$ were significantly increased in diabetic rats. Serum TRAP is a biomarker of osteoclast activity and hydroxyproline is considered as an end product of collagen degradation. The increased levels of these two proteins indicate the excessive bone resorption in the diabetic rats. Further, all the treatments significantly decreased the serum TRAP activity in the DC + CQ1 $(P<0.05)$,
$\mathrm{DC}+\mathrm{CQ} 2(P<0.01)$, and DC + INS $(P<0.01)$ groups in comparison to diabetic nontreated rats (Table 2 ). Similarly, the hydroxyproline levels were also significantly decreased in the DC + CQ1 $(P<0.05), \mathrm{DC}+\mathrm{CQ} 2(P<0.05)$, and DC + INS $(P<0.01)$ groups in comparison to DC group (Table 2).

\section{Discussion}

Results of the present study showed that PECQ treatment is effective against type $1 \mathrm{DM}$ - induced histological, biomechanical, and biochemical changes in the bone. Further, these 


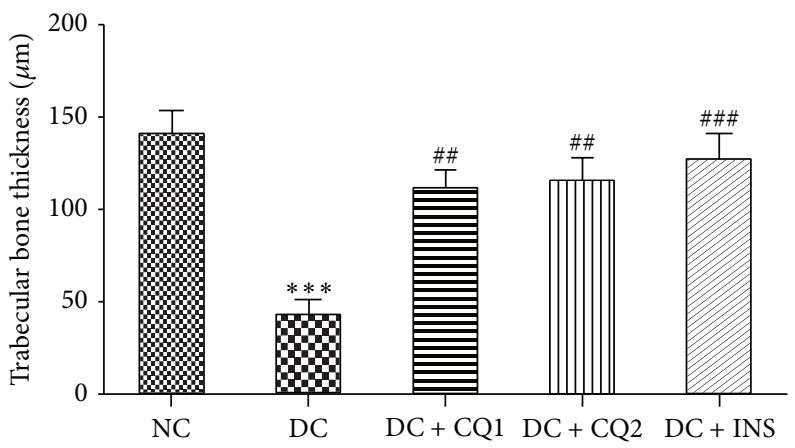

(a)

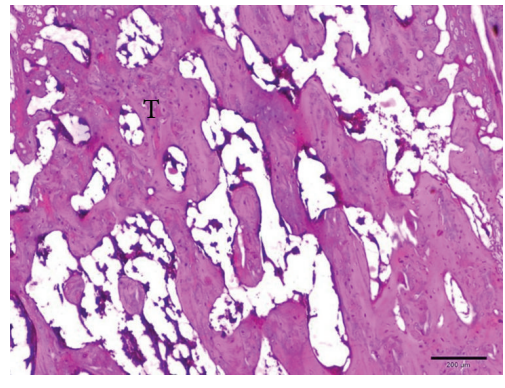

NC

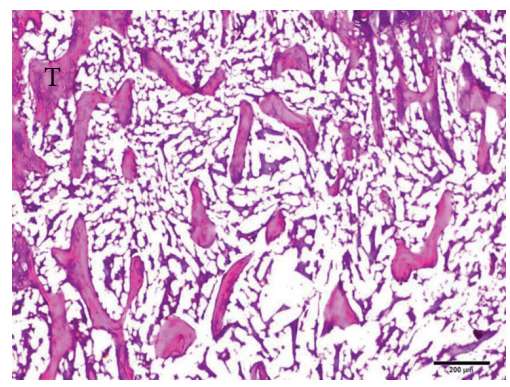

DC

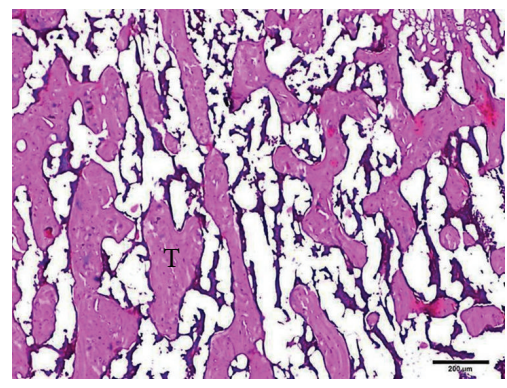

$\mathrm{DC}+\mathrm{CQ} 1$

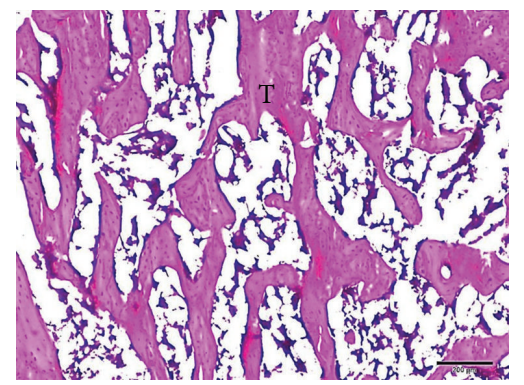

$\mathrm{DC}+\mathrm{CQ} 2$

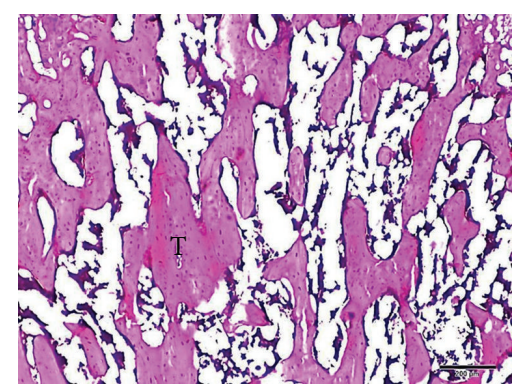

DC + INS

(b)

FIGURE 2: (a) Effect of PECQ on mean thickness of trabecular bone in the metaphyseal region. Thickness of the trabecular bone significantly decreased in diabetic control (DC) rats when compared to normal control (NC) rats. However, treatment with two different doses of PECQ $(\mathrm{DC}+\mathrm{CQ1}$ and $\mathrm{DC}+\mathrm{CQ} 2)$ or with insulin (DC + INS) showed a significant increase in the bone thickness, when compared to diabetic nontreated rats. ${ }^{* * *} P<0.001$ when compared to NC group; ${ }^{\# \#} P<0.001$, ${ }^{\# \#} P<0.01$ when compared to DC group. (b) Photomicrographs of the trabecular bone in metaphyseal region. Thinner, disrupted, and reduced number of trabeculae were observed in the diabetic control group (DC) when compared to the normal control group (NC). Further treatment with two doses of PECQ (DC + CQ1, DC + CQ2) and insulin (DC + INS) improved the trabecular bone growth. T: trabecular bone; H and E staining, scale bar: $200 \mu \mathrm{m}$.

results are comparable to the effects of insulin treatment. Unlike insulin, PECQ did not reduce the blood glucose levels in the diabetic rats indicating that PECQ has shown its effect through mechanisms other than the glycemic control.

The association between type $1 \mathrm{DM}$ and osteoporosis has been accepted widely both experimentally $[37,38]$ and clinically $[16,39]$. Based on the existing data, it is uncertain that reduced bone mass in diabetic rats is either due to defective bone formation or due to reduced bone growth [40]. Previous studies have reported the histological changes in both cortical bone $[13,41,42]$ and trabecular bone $[43,44]$ in diabetic animals. Our results are consistent with those of earlier studies wherein the diabetic rats showed a marked reduction in the thickness of both cortical and trabecular bones. The diabetic rats also had decreased dry weight of the bone compared to healthy animals. Bone strength depends on the integrity of the two components of bone: cortical and trabecular bone. Previous studies on the effect of diabetes on bone strength have reported conflicting data. In few reports bone strength is increased [20,21]; meanwhile it is reduced in others $[13,42]$. Our results indicate that diabetic rats seem to have lower bone strength.

It has been hypothesized that inflammation plays a role in the pathology of diabetes- induced bone complications [45]. Cytokines such as IL-6, IL-1 $\beta$, and TNF- $\alpha$ are known for their involvement in the process of bone loss in diabetes 


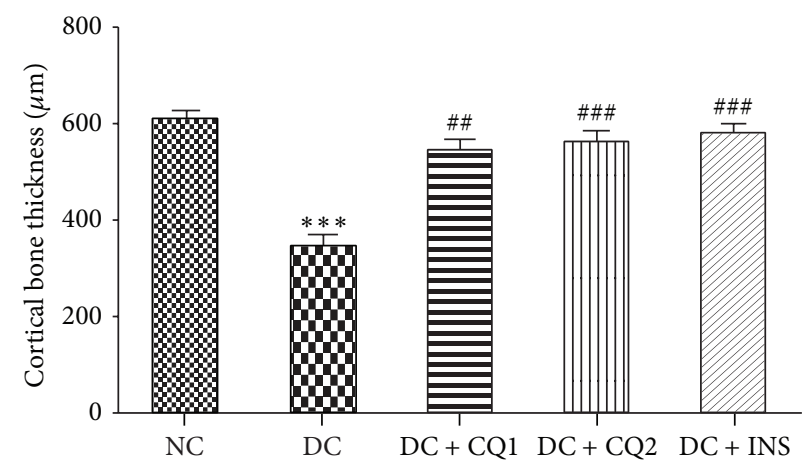

(a)
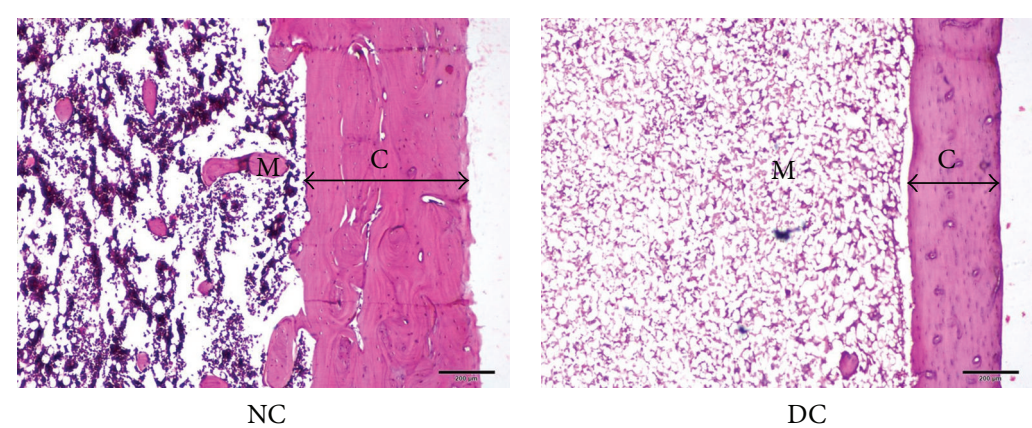

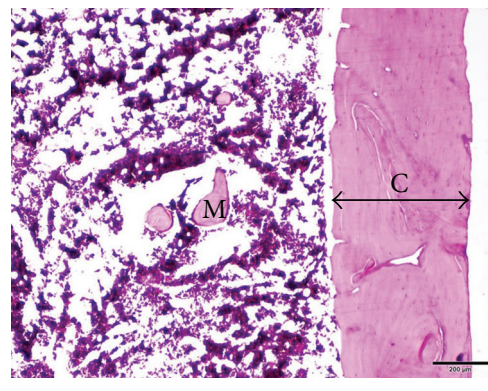

$\mathrm{DC}+\mathrm{CQ} 1$

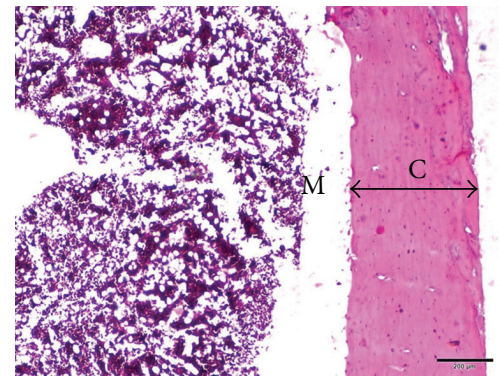

$\mathrm{DC}+\mathrm{CQ} 2$

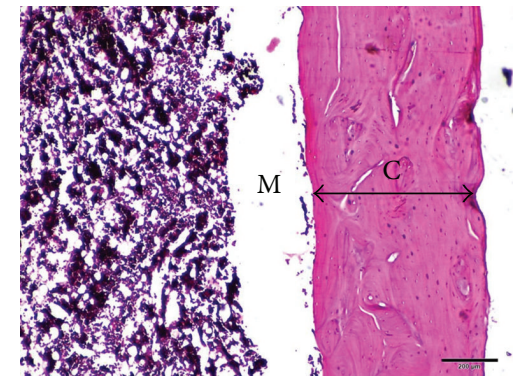

DC + INS

(b)

Figure 3: (a) Effect of PECQ on mean thickness of cortical bone. Thickness of the cortical bone significantly decreased in diabetic control (DC) rats when compared to normal control (NC) rats. Treatment with two different doses of PECQ (DC + CQ1 and DC + CQ2) or with insulin (DC + INS) significantly increased the bone thickness in diabetic rats when compared to nontreated diabetic rats. ${ }^{* * *} P<0.001$ when compared to NC group; ${ }^{\# \#} P<0.001,{ }^{\# \#} P<0.01$ when compared to DC group. (b) Photomicrographs of cortical bone. Thickness of the cortical bone was significantly less in the diabetic control group (DC) when compared to normal control group (NC). Further treatment with two doses of the PECQ (DC + CQ1, DC + CQ2) and insulin (DC + INS) improved the cortical bone growth. C: cortical bone; M: medullary cavity; $\mathrm{H}$ and $\mathrm{E}$ staining, scale bar: $200 \mu \mathrm{m}$.

[46]. LT- $\beta$, IL-6, IFN- $\gamma$, and TNF- $\alpha$ were found to increase in the diabetic bone [45]. Anti-inflammatory activity of CQ has been shown by previous studies [47, 48]. Ethanol fraction of $C Q$ has been shown to decrease the serum levels of the proinflammatory cytokines TNF- $\alpha$, IL-1 $\beta$, and IL-6 in ovariectomized mice [48]. The positive effect of PECQ on bone loss in the diabetic state could be due to its antiinflammatory property. However, experimental evidence is required to confirm effect of PECQ on both bone and serum cytokines levels in diabetic state.

Hyperglycemia is known to alter the antioxidant defense by increasing the polyol pathway flux, rate of formation of the ROS, and glucose-derived advanced glycosylation end products [49]. Previous studies have confirmed the association between oxidative stress and the development of osteopenia in DM [50,51]. ROS is known to stimulate bone resorption by altering the function of osteoclasts [52]. Bai et al., have observed that oxidative stress can inhibit the differentiation of osteoblast cells [53]. Previous studies have demonstrated antioxidant and free radical scavenging potential of CQ both in vitro and in vivo $[54,55]$. Hence, beneficial effects of PECQ against bone damage in diabetic rats can be correlated to its antioxidant properties.

Endocrine factor such as insulin-like growth factor-1 (IGF-1) signaling is found to be downregulated in both humans and animal models with type I DM [56, 57]. 


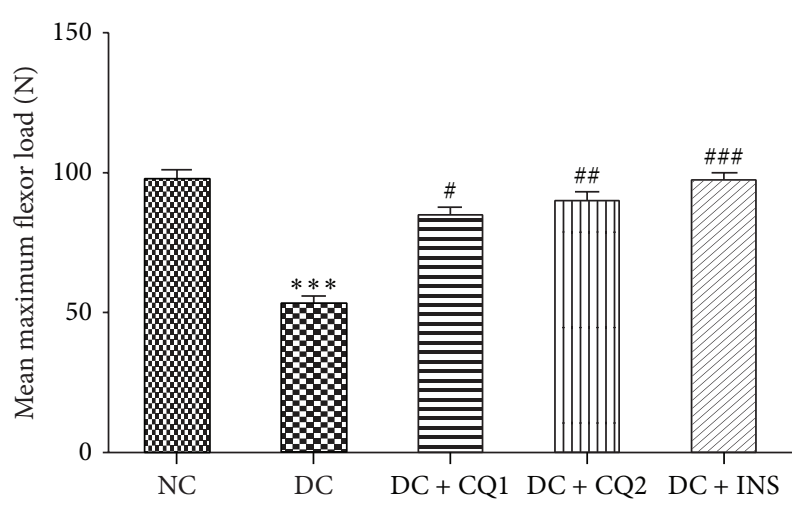

FIGURE 4: Effect of PECQ on mean maximum flexor load of femur. Mean maximum flexor load significantly decreased in diabetic control (DC) rats when compared to normal control (NC) rats. Treatment with two different doses of PECQ (DC + CQ1 and DC + CQ2) or with insulin (DC + INS) significantly increased the mean maximum flexor load in diabetic rats when compared to DC rats. ${ }^{* * *} P<0.001$ when compared to NC group; ${ }^{\# \# \#} P<0.001,{ }^{\# \#} P<0.01$, and ${ }^{\#} P<0.05$ when compared to DC group.

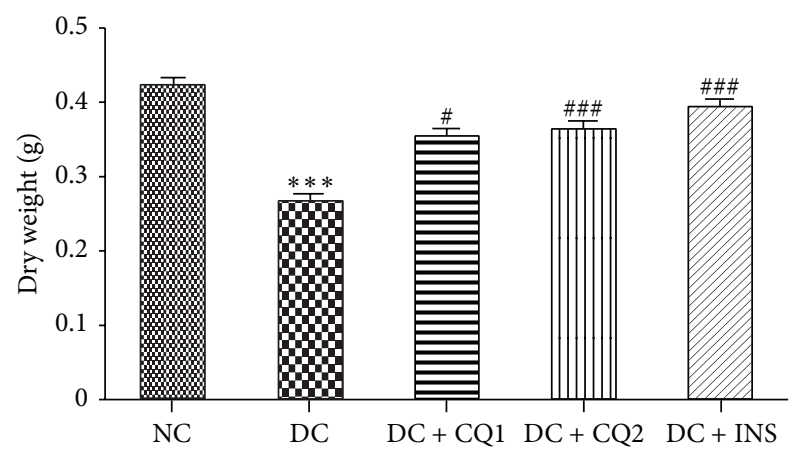

FIGURE 5: Effect of PECQ on dry weight of the tibia. Dry weight of the tibia significantly decreased in diabetic control (DC) rats when compared to normal control (NC) rats. Treatment with two different doses of PECQ (DC + CQ1 and DC + CQ2) or with insulin (DC + INS) significantly increased the dry weight in diabetic rats when compared to DC rats. ${ }^{* * *} P<0.001$ when compared to NC group; ${ }^{\# \# \# P} P<0.001,{ }^{\#} P<0.05$ when compared to DC group.

Decreased bone mineral density and altered osteoblast differentiation are seen with low serum levels of IGF-1 [58, 59]. Further, it has been demonstrated that improving the serum IGF-1 levels can prevent bone loss in diabetic rats [60]. Muthusami et al. studied the effect of ethanol extract CQ on IGF system components and found that CQ can enhance the mRNA expression of IGF-IR, IGF-I, and IGF-II [61]. Based on the above facts, we hypothesize that PECQ could have prevented the bone loss in diabetic rats by increasing the expression of IGF system components. However, further studies are required to confirm the effect of the PECQ on IGF system components in hyperglycemic conditions.

Earlier studies have demonstrated the beneficial effect of synthetic estrogen E2 against the bone loss in hyperglycemic state $[25,26]$. The positive effect of PECQ on bone changes in diabetic rats observed in the present study could be due to the phytoestrogen steroids present in it $[32,33]$, which may increase the bone formation and/or accelerate bone growth. Alterations in the mineral metabolism and bone remodeling factors are claimed to be the possible mechanism of diabetesinduced osteoporosis [17]. It has been observed that altered bone turnover in diabetes is usually associated with the changes in serum ALP, TRAP, and hydroxyproline activities [25]. In the present study, ALP levels were significantly increased in diabetic rats. Serum ALP is considered as a biomarker of osteoblast activity. The increased ALP levels in the diabetic rats indicate the compensatory mechanism of the body against diabetes-induced bone damage. Administration of two doses of PECQ and INS showed further increase in the ALP levels compared to diabetic group. This result indicates that PECQ enhances osteoblast proliferation and thus facilitates the bone formation. An in vitro study has demonstrated the stimulatory effect of E2 on differentiation of bone marrow mesenchymal stem cells, in hyperglycemic conditions [62]. The beneficial effect of PECQ on ALP activity could be due to estrogen-mimicking action of phytoestrogen steroids present in it $[32,33]$.

Compared to normal control group, serum TRAP levels are significantly increased in diabetic animals. Serum TRAP is a biomarker of osteoclast activity. The increased levels of this protein indicate that the reduced bone mass in the diabetic rats is also due to excessive bone resorption. With respect to serum TRAP activity, our results are consistent with previous findings [25]. However, Waud et al. have observed normal TRAP activity in the experimental diabetic animals [37]. In another study on patients with type I diabetes, TRAP activity was found to be low [63]. Administration of PECQ and INS significantly decreased the TRAP levels compared to diabetic animals. The observed effect of the PECQ on the TRAP activity could be due to the direct action of the phytoestrogen steroids present in it $[32,33]$. This can be explained based on the fact that estrogen can accelerate the apoptosis of matured osteoclast cells [64].

Serum hydroxyproline is a breakdown product of collagen. In the present study, the hydroxyproline levels were significantly increased in the diabetic rats indicating the inhibitory effect of diabetes on bone collagen. This result is consistent with that of the previous study [25]. Treatment with PECQ and INS significantly decreased the serum hydroxyproline levels. Gopalakrishnan et al. in their in vitro study demonstrated the positive effect of E2 on mineralization and histochemical staining for collagen in the bone marrow stromal cells [62]. The positive effect of the PECQ could be due to the estrogen-like action of phytoestrogen steroids [32, 33] on collagen formation.

\section{Conclusion}

Preliminary results of the present study indicate that PECQ is effective in improving histological, biomechanical, and biochemical changes of bone in diabetic rats. Though exact mechanism of action of PECQ has not been ascertained, the observed effect of PECQ could be due to its osteogenic, antioxidant, and anti-inflammatory properties. 
However, in this context, extensive studies are required to confer the exact mechanism of PECQ on bone cells in hyperglycemic conditions.

\section{Conflict of Interests}

The authors declare that there is no conflict of interests regarding the publication of this paper.

\section{References}

[1] B. Balkau, M. A. Charles, and E. Eschwege, "Discussion épidémiologique des nouveaux critères de diabète," Médecine Thérapeutique Endocrinologie \& Reproduction, vol. 2, no. 3, pp. 229-234, 2000.

[2] J. V. Santiago, W. H. McAlister, S. K. Ratzan et al., "Decreased cortical thickness and osteopenia in children with diabetes mellitus," The Journal of Clinical Endocrinology and Metabolism, vol. 45, no. 4, pp. 845-848, 1977.

[3] M. E. Levin, V. C. Boisseau, and L. V. Avioli, "Effects of diabetes mellitus on bone mass in juvenile and adult onset diabetes," The New England Journal of Medicine, vol. 294, no. 5, pp. 241-245, 1976.

[4] I. de Leeuw and R. Abs, "Bone mass and bone density in maturity-type diabetics measured by the ${ }^{125} \mathrm{I}$ photonabsorption technique," Diabetes, vol. 26, no. 12, pp. 1130-1135, 1977.

[5] H. Heath III, P. W. Lambert, F. J. Service, and S. B. Arnaud, "Calcium homeostasis in diabetes mellitus," The Journal of Clinical Endocrinology and Metabolism, vol. 49, no. 3, pp. 462466, 1979.

[6] P. McNair, S. Madsbad, C. Christiansen, O. K. Faber, I. Transbol, and C. Binder, "Osteopenia in insulin treated diabetes mellitus. Its relation to age at onset, sex and duration of disease," Diabetologia, vol. 15, no. 2, pp. 87-90, 1978.

[7] Y. Seino and H. Ishida, "Diabetic osteopenia: pathophysiology and clinical aspects," Diabetes/Metabolism Reviews, vol. 11, no. 1, pp. 21-35, 1995.

[8] J. Levy, I. Reid, L. Halstad, J. R. Gavin III, and L. V. Avioli, "Abnormal cell calcium concentrations in cultured bone cells obtained from femurs of obese and noninsulin-dependent diabetic rats," Calcified Tissue International, vol. 44, no. 2, pp. 131-137, 1989.

[9] L. Cozen, "Does diabetes delay fracture healing?" Clinical Orthopaedics and Related Research, vol. 82, pp. 134-140, 1972.

[10] R. Shires, S. L. Teitelbaum, M. A. Bergfeld, M. D. Fallon, E. Slatopolsky, and L. V. Avioli, "The effect of streptozotocininduced chronic diabetes mellitus on bone and mineral homeostasis in the rat," Journal of Laboratory and Clinical Medicine, vol. 97, no. 2, pp. 231-240, 1981.

[11] K. Suzuki, N. Miyakoshi, T. Tsuchida, Y. Kasukawa, K. Sato, and E. Itoi, "Effects of combined treatment of insulin and human parathyroid hormone(1-34) on cancellous bone mass and structure in streptozotocin-induced diabetic rats," Bone, vol. 33, no. 1, pp. 108-114, 2003.

[12] J. J. Tomasek, S. W. Meyers, J. B. Basinger, D. T. Green, and R. L. Shew, "Diabetic and age-related enhancement of collagenlinked fluorescence in cortical bones of rats," Life Sciences, vol. 55, no. 11, pp. 855-861, 1994.

[13] J. Verhaeghe, A. M. Suiker, T. A. Einhorn et al., "Brittle bones in spontaneously diabetic female rats cannot be predicted by bone mineral measurements: studies in diabetic and ovariectomized rats," Journal of Bone and Mineral Research, vol. 9, no. 10, pp. 1657-1667, 1994.

[14] J. Verhaeghe, A. M. Suiker, B. L. Nyomba et al., "Bone mineral homeostasis in spontaneously diabetic BB rats. II. Impaired bone turnover and decreased osteocalcin synthesis," Endocrinology, vol. 124, no. 2, pp. 573-582, 1989.

[15] J. Verhaeghe, E. van Herck, W. J. Visser et al., "Bone and mineral metabolism in $\mathrm{BB}$ rats with long-term diabetes: decreased bone turnover and osteoporosis," Diabetes, vol. 39, no. 4, pp. 477-482, 1990.

[16] S. A. G. Kemink, A. R. M. M. Hermus, L. M. J. W. Swinkels, J. A. Lutterman, and A. G. H. Smals, "Osteopenia in insulindependent diabetes mellitus: prevalence and aspects of pathophysiology," Journal of Endocrinological Investigation, vol. 23, no. 5, pp. 295-303, 2000.

[17] D. T. Ward, S. K. Yau, A. P. Mee et al., "Functional, molecular, and biochemical characterization of streptozotocin-induced diabetes," Journal of the American Society of Nephrology, vol. 12, no. 4, pp. 779-790, 2001.

[18] P. K. Dixit and R. A. Ekstrom, "Retardation of bone fracture healing in experimental diabetes," Indian journal of medical research, vol. 85, pp. 426-435, 1987.

[19] H. A. Beam, J. R. Parsons, and S. S. Lin, "The effects of blood glucose control upon fracture healing in the BB Wistar rat with diabetes mellitus," Journal of Orthopaedic Research, vol. 20, no. 6, pp. 1210-1216, 2002.

[20] J. R. Funk, J. E. Hale, D. Carmines, H. L. Gooch, and S. R. Hurwitz, "Biomechanical evaluation of early fracture healing in normal and diabetic rats," Journal of Orthopaedic Research, vol. 18, no. 1, pp. 126-132, 2000.

[21] G. K. Reddy, L. Stehno-Bittel, S. Hamade, and C. S. Enwemeka, "The biomechanical integrity of bone in experimental diabetes," Diabetes Research and Clinical Practice, vol. 54, no. 1, pp. 1-8, 2001.

[22] J. Griffet, A. Chevallier, E. Accorsi, T. El Hayek, G. Odin, and B. Pebeyre, "Osteosynthesis of diaphyseal fracture by Ossatite experimental study in rat," Biomaterials, vol. 20, no. 6, pp. 511$515,1999$.

[23] S. Pramanik, A. K. Agarwal, K. N. Rai, and A. Garg, "Development of high strength hydroxyapatite by solid-state-sintering process," Ceramics International, vol. 33, no. 3, pp. 419-426, 2007.

[24] J. R. Woodard, A. J. Hilldore, S. K. Lan et al., "The mechanical properties and osteoconductivity of hydroxyapatite bone scaffolds with multi-scale porosity," Biomaterials, vol. 28, no. 1, pp. 45-54, 2007.

[25] V. Gopalakrishnan, J. Arunakaran, M. M. Aruldhas, and N. Srinivasan, "Effects of streptozotocin-induced diabetes mellitus on some bone turnover markers in the vertebrae of ovary-intact and ovariectomized adult rats," Biochemistry and Cell Biology, vol. 84, no. 5, pp. 728-736, 2006.

[26] J. Verhaeghe, J. S. Thomsen, R. van Bree, E. van Herck, R. Bouillon, and L. Mosekilde, "Effects of exercise and disuse on bone remodeling, bone mass, and biomechanical competence in spontaneously diabetic female rats," Bone, vol. 27, no. 2, pp. 249-256, 2000.

[27] A. Shirwaikar, S. Khan, and S. Malini, "Antiosteoporotic effect of ethanol extract of Cissus quadrangularis Linn. on ovariectomized rat," Journal of Ethnopharmacology, vol. 89, no. 2-3, pp. 245-250, 2003. 
[28] E. M. Williamson, Major Herbs of Ayuraveda, Churchill Livingstone, London, UK, 2002.

[29] S. J. Stohs and S. D. Ray, "A review and evaluation of the efficacy and safety of Cissus quadrangularis extracts," Phytotherapy Research, vol. 27, no. 8, pp. 1107-1114, 2013.

[30] B. K. Potu, M. S. Rao, G. K. Nampurath, M. R. Chamallamudi, S. R. Nayak, and H. Thomas, "Anti-osteoporotic activity of the petroleum ether extract of Cissus quadrangularis Linn. in ovariectomized wistar rats," Chang Gung Medical Journal, vol. 33, no. 3, pp. 252-257, 2010.

[31] T. Pathomwichaiwata, W. Suvitayavatb, A. Sailasutac, P. Piyachaturawatd, N. Soonthornchareonnone, and S. Prathanturaruga, "Antiosteoporotic effect of sequential extracts and freezedried juice of Cissus quadrangularis L. in ovariectomized mice," Asian Biomedicine, vol. 6, no. 3, pp. 377-384, 2012.

[32] G. C. Prasad and K. N. Udupa, "Pathways and site of action of a phytogenic steroid from Cissus quadrangularis," Journal of Research in Indian Medicine, vol. 4, article 132, 1972.

[33] U. M. Aswar, V. Mohan, and S. L. Bodhankar, "Antiosteoporotic activity of phytoestrogen-rich fraction separated from ethanol extract of aerial parts of Cissus quadrangularis in ovariectomized rats," Indian Journal of Pharmacology, vol. 44, no. 3, pp. 345-350, 2012.

[34] B. K. Potu, K. M. Bhat, M. S. Rao et al., "Petroleum ether extract of Cissus quadrangularis (linn.) enhances bone marrow mesenchymal stem cell proliferation and facilitates osteoblastogenesis," Clinics, vol. 64, no. 10, pp. 993-998, 2009.

[35] R. E. Neuman and M. A. Logan, "The determination of collagen and elastin in tissues," The Journal of Biological Chemistry, vol. 186, no. 2, pp. 549-556, 1950.

[36] N. P. Reddy, M. Lakshmana, and U. V. Udupa, "Antiosteoporotic activity of OST-6(Osteocare), a herbomineral preparation in calcium deficient ovariectomized rats," Phytotherapy Research, vol. 18, no. 1, pp. 25-29, 2004.

[37] C. E. Waud, S. C. Marks Jr., R. Lew, and D. T. Baran, "Bone mineral density in the femur and lumbar vertebrae decreases after twelve weeks of diabetes in spontaneously diabetic-prone BB/Worcester rats," Calcified Tissue International, vol. 54, no. 3 , pp. 237-240, 1994.

[38] S. Herrero, O. M. Calvo, C. García-Moreno et al., "Low bone density with normal bone turnover in ovariectomized and streptozotocin-induced diabetic rats," Calcified Tissue International, vol. 62, no. 3, pp. 260-265, 1998.

[39] T. Miazgowski and S. Czekalski, "A 2-year follow-up study on bone mineral density and markers of bone turnover in patients with long-standing insulin-dependent diabetes mellitus," Osteoporosis International, vol. 8, no. 5, pp. 399-403, 1998.

[40] M. J. Silva, M. D. Brodt, M. A. Lynch et al., "Type 1 diabetes in young rats leads to progressive trabecular bone loss, cessation of cortical bone growth, and diminished whole bone strength and fatigue life," Journal of Bone and Mineral Research, vol. 24, no. 9, pp. 1618-1627, 2009.

[41] P. K. Dixit and R. A. Ekstrom, "Decreased breaking strength of diabetic rat bone and its improvement by insulin treatment," Calcified Tissue International, vol. 32, no. 3, pp. 195-199, 1980.

[42] T. A. Einhorn, A. L. Boskey, C. M. Gundberg, V. J. Vigorita, V. J. Devlin, and M. M. Beyer, "The mineral and mechanical properties of bone in chronic experimental diabetes," Journal of Orthopaedic Research, vol. 6, no. 3, pp. 317-323, 1988.
[43] T. Tsuchida, K. Sato, N. Miyakoshi et al., "Histomorphometric evaluation of the recovering effect of human parathyroid hormone (1-34) on bone structure and turnover in streptozotocininduced diabetic rats," Calcified Tissue International, vol. 66, no. 3, pp. 229-233, 2000.

[44] W. G. Goodman and M. T. Hori, "Diminished bone formation in experimental diabetes. Relationship to osteoid maturation and mineralization," Diabetes, vol. 33, no. 9, pp. 825-831, 1984.

[45] K. J. Motyl, S. Botolin, R. Irwin et al., "Bone inflammation and altered gene expression with type I diabetes early onset," Journal of Cellular Physiology, vol. 218, no. 3, pp. 575-583, 2009.

[46] R. Blakytny, M. Spraul, and E. B. Jude, "Review: the diabetic bone: a cellular and molecular perspective," The International Journal of Lower Extremity Wounds, vol. 10, no. 1, pp. 16-32, 2011.

[47] A. M. Bhujade, S. Talmale, N. Kumar et al., "Evaluation of Cissus quadrangularis extracts as an inhibitor of COX, 5-LOX, and proinflammatory mediators," Journal of Ethnopharmacology, vol. 141, no. 3, pp. 989-996, 2012.

[48] J. Banu, E. Varela, A. N. Bahadur, R. Soomro, N. Kazi, and G. Fernandes, "Inhibition of bone loss by Cissus quadrangularis in mice: a preliminary report," Journal of Osteoporosis, vol. 2012, Article ID 101206, 10 pages, 2012.

[49] T. Oyama, Y. Miyasita, H. Watanabe, and K. Shirai, "The role of polyol pathway in high glucose-induced endothelial cell damages," Diabetes Research and Clinical Practice, vol. 73, no. 3, pp. 227-234, 2006.

[50] K. Ding, Z. Wang, M. W. Hamrick et al., "Disordered osteoclast formation in RAGE-deficient mouse establishes an essential role for RAGE in diabetes related bone loss," Biochemical and Biophysical Research Communications, vol. 340, no. 4, pp. 10911097, 2006.

[51] Y. Hamada, S. Kitazawa, R. Kitazawa, H. Fujii, M. Kasuga, and M. Fukagawa, "Histomorphometric analysis of diabetic osteopenia in streptozotocin-induced diabetic mice: a possible role of oxidative stress," Bone, vol. 40, no. 5, pp. 1408-1414, 2007.

[52] I. R. Garrett, B. F. Boyce, R. O. Oreffo, L. Bonewald, J. Poser, and G. R. Mundy, "Oxygen-derived free radicals stimulate osteoclastic bone resorption in rodent bone in vitro and in vivo," The Journal of Clinical Investigation, vol. 85, no. 3, pp. 632-639, 1990.

[53] X.-C. Bai, D. Lu, J. Bai et al., "Oxidative stress inhibits osteoblastic differentiation of bone cells by ERK and NF- $\kappa \mathrm{B}$," Biochemical and Biophysical Research Communications, vol. 314, no. 1, pp. 197-207, 2004.

[54] M. Jainu and C. S. Devi, "In vitro and in vivo evaluation of freeradical scavenging potential of Cissus quadrangularis," African Journal of Biomedical Research, vol. 8, no. 2, pp. 95-99, 2005.

[55] K. N. C. Murthy, A. Vanitha, M. M. Swamy, and G. A. Ravishankar, "Antioxidant and antimicrobial activity of Cissus quadrangularis L," Journal of Medicinal Food, vol. 6, no. 2, pp. 99-105, 2003.

[56] R. G. Clark, "Recombinant human insulin-like growth factor I (IGF-I): risks and benefits of normalizing blood IGF-I concentrations," Hormone Research in Paediatrics, vol. 62, supplement 1, pp. 93-100, 2004.

[57] P. M. Jehle, D. R. Jehle, S. Mohan, and B. O. Böhm, "Serum levels of insulin-like growth factor system components and relationship to bone metabolism in type 1 and type 2 diabetes mellitus patients," The Journal of Endocrinology, vol. 159, no. 2, pp. 297-306, 1998.

[58] C. J. Rosen, C. L. Ackert-Bicknell, M. L. Adamo et al., "Congenic mice with low serum IGF-I have increased body fat, reduced 
bone mineral density, and an altered osteoblast differentiation program," Bone, vol. 35, no. 5, pp. 1046-1058, 2004.

[59] M. Zhang, S. Xuan, M. L. Bouxsein et al., "Osteoblast-specific knockout of the insulin-like growth factor (IGF) receptor gene reveals an essential role of IGF signaling in bone matrix mineralization," The Journal of Biological Chemistry, vol. 277, no. 46, pp. 44005-44012, 2002.

[60] J. Verhaeghe, A. M. Suiker, W. J. Visser, E. van Herck, R. van Bree, and R. Bouillon, "The effects of systemic insulin, insulinlike growth factor-I and growth hormone on bone growth and turnover in spontaneously diabetic BB rats," The Journal of Endocrinology, vol. 134, no. 3, pp. 485-492, 1992.

[61] S. Muthusami, I. Ramachandran, S. Krishnamoorthy, R. Govindan, and S. Narasimhan, "Cissus quadrangularis augments IGF system components in human osteoblast like SaOS-2 cells," Growth Hormone and IGF Research, vol. 21, no. 6, pp. 343-348, 2011.

[62] V. Gopalakrishnan, R. C. Vignesh, J. Arunakaran, M. M. Aruldhas, and N. Srinivasan, "Effects of glucose and its modulation by insulin and estradiol on BMSC differentiation into osteoblastic lineages," Biochemistry and Cell Biology, vol. 84, no. 1, pp. 93-101, 2006.

[63] M. M. C. Pastor, P. J. López-Ibarra, F. Escobar-Jiménez, M. D. Serrano Pardo, and A. García-Cervigón, "Intensive insulin therapy and bone mineral density in type 1 diabetes mellitus: a prospective study," Osteoporosis International, vol. 11, no. 5, pp. 455-459, 2000.

[64] D. E. Hughes, A. Dai, J. C. Tiffee, H. H. Li, G. R. Munoy, and B. F. Boyce, "Estrogen promotes apoptosis of murine osteoclasts mediated by TGF- $\beta$," Nature Medicine, vol. 2, no. 10, pp. 1132 1136, 1996. 

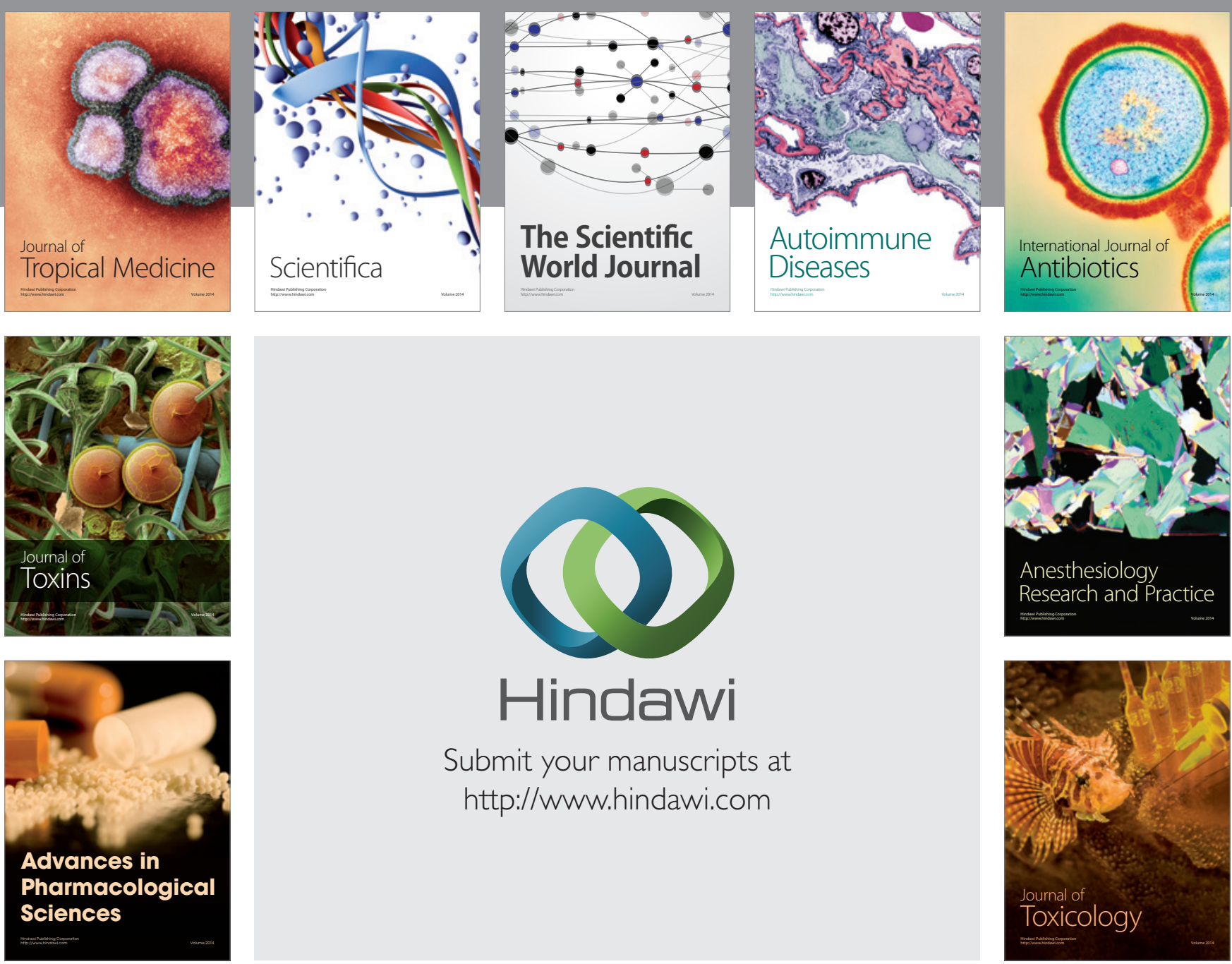

\section{Hindawi}

Submit your manuscripts at

http://www.hindawi.com
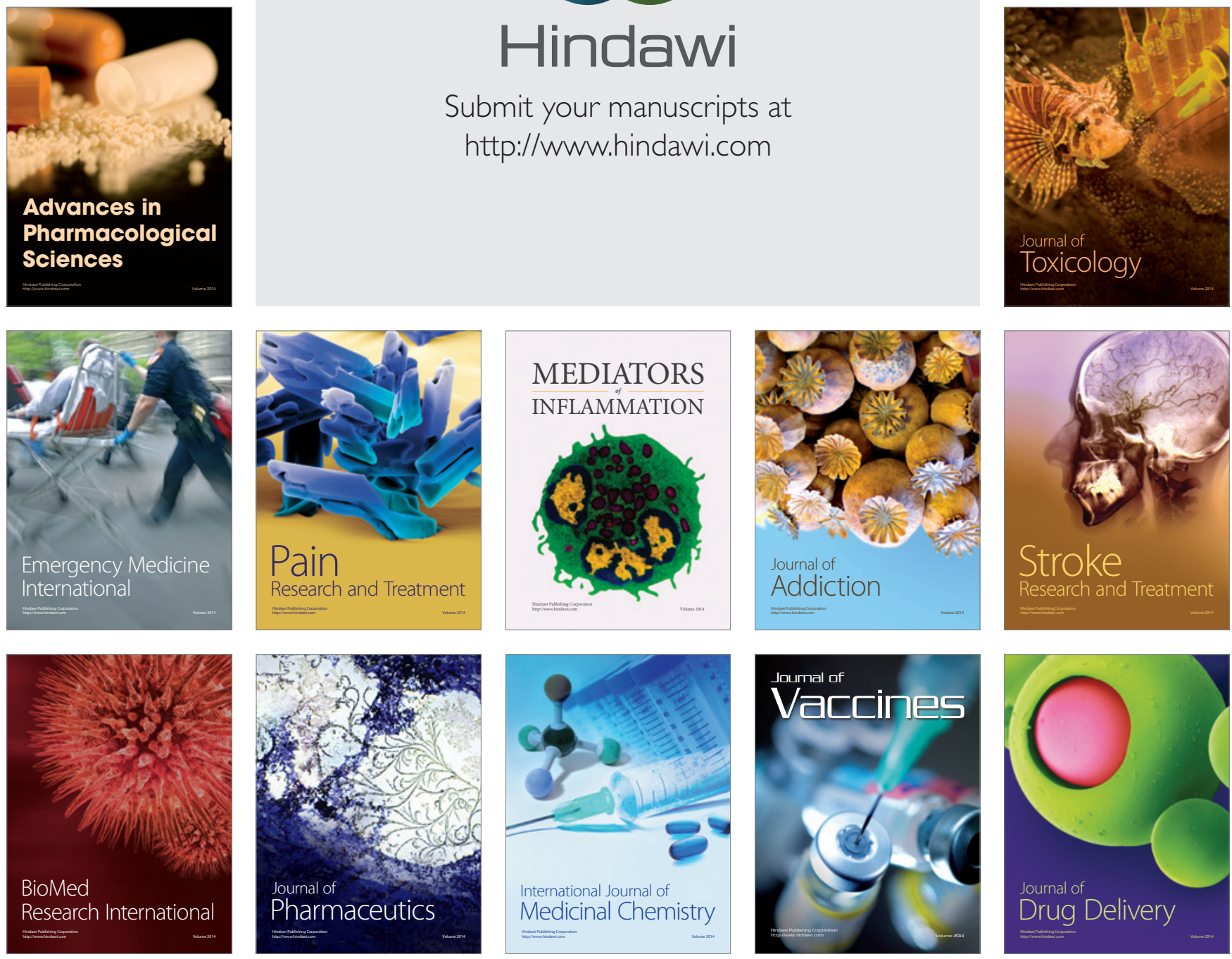